Wenn Quecksilbermelall, Schwefel und Salmiakgeist zusammen erhitzt werden, só wird das Quecksilber vom Oxyde des Ammoniums gesauerslofft, es bildet sich gleicher Zeit Schwefelammonium, diess letztere zersetzt das oxydirte Quecksilber zu Schwefelquecksilber, wodurch wieder Ammoniumoxyd gebildet wird; dieser Austausch hat, so lange als Metall vorhanden ist, seinen Kreislauf. Hierbei bemerkt man keine Entwịckelung von Hydrothionsäure, und lïsst man die Mischung erkalten, so wird zweiles Schwefelammonium über dem Niederschlag vorgefunden.

\title{
Eisenjodür in einer passlichen Form als $\mathrm{Me}-$ dicament;

\author{
von \\ C. E. Fischer,
} in Riga.

Das Eisenjodïr ist in neuerer Zeit nicht selten als MIedicament angewendet worden uud scheint als solches namentlich in Frankreich und Norddeutschland in Aufnahme gekommen zu seyn, wie es denn auch im pharmaceulischen Centralblatte Nr. 20. Jahrgang 1838 mit Hinweisung auf die Gaz. des hopit. ${ }^{83} 7$. Nr. 125. von L ec bell e als Heilmittel in syphilitischen Krankheiten angepriesen wird. Eben so ist auch die Vorschrift zu dem Ferrum jodatum vor Kurzem in den ,Zusätzen zu den Vorschriften des Codex medicamentarius hamburgensis" erschienen, wornach 1 Theil Jod $\frac{5}{2}$ Theil Eisenfeile und 4 Theile Wasser so lange in gegenseitiger Berührung gelassen werden sollen, bis die Flüssigkeit ganz farblos erscheint. Hierauf soll aber das Filtrat nicht zur Krystallisation gebracht, sondern die Lauge so weit abgedampft werden, bis sich ein graues Krystallhäutchen bildet 
und eine herausgenommene Probe sogleich und vollkommen erstarrt. Die fliessende Masse soll man in eine eiserne, mit Mandelöl ausgestrichene Form ausgiessen und die erkalteten, dünnen Cylinder sogleich in kleinen wohlzuverschliessenden Gläsern aufbewahren.

Bei dieser Darstellungsweise erhält man aber nach der Erfahrung Anderer und nach eigenem Versuche ein Präparat, welches beim Auflösen in Wasser stets eine nambafle Menge von Eisenoxyd abscheidet, weil während des Abdampfens bis zu dem vorgeschriebenen Puncle erst Eisenjodid entsteht und dann auch Jod verflüchtigt wird. Bei der Dispensation dieses Salzes muss daher stets die Auflösung filtrirt-werden, und durch das rückständig gebliebene Eiseñoxyd muss eine Differenz in der verordneten Quantilät des Eisenjodürs entstelsen. Auch die Anwendung des krystallisirten Salzes scheint, weil dasselbe Jeicht zerfliesst, ebenfalls nicht ganz zweckmässig.

Um nun das Ferrum jodatum in einer zur Aufbewahrung und Verabreichung schicklichen Form als 'Arzneimittel vorräıbig zu haben und unzersetzt anzuwenden, Jürfte wohl die von dem Herrn Apotheker Frederking in Riga vor Kurzem vorgeschlagene und dem Herrn Hofrath Wackenroder zur Prüfung mitgetheilte Methode einige Beachtung verdienen.

Frederking schlägt vor: 1 Theil Jod nnit $\frac{x}{2}$ Theil Eisenfeile und 6 Theilen Wasser so lange in gegenseitiger Berührung stehen zu lassen, bis die Fïssigkeit vởllig farblos erscheint, hierauf zu filtriren und den Ruicksland mit warmen Wasser gut auszuwaschen. Zu dem Fillrate setzt man 2 Theile Zucker und dampft das Ganze bis zur Syrupsconsistenz ab. Dieser Syrup soll, 14 Tage der freien Luft ausgesetzt, eben so auch dessen wässrige Auflösung nicht das mindeste Eisenoxyd abscheiden. Nach Frederking gebén 
100 Gran Jod, 5o Gran Eisen und 200 Gran Zucker $=1$ Unze Syrup, worin olngefähr $\frac{1}{4}$ Jodeisen enthalten ist.

Von 3,o Grm. Jod, 1,5 Grm. Eisen, 18,o Grm. Wasser und 6,o Grm. Zucker erhielt ich 10,0 Grm. eines schwarzgrünen Syrups, welcher binnen acht Wochen in einer leicht bedeckten Porzellanschaale nicht den geringsten Bodensatz absetzle und beim Vermischen mit Wasser eine klare und fast farblose Flïssigkeit gab. Es war darin Eisenjodür mit einer äusserst geringen Menge Eisenjodid enthalten, denn Aetzkali und Aetzammoniak gaben in der verdünnten Auflösung dieses Syrups graugrïne, kohlensaures Natron und 'kohlensaures Ammoniak fast gainz weisse Niederschläge. Desgleichen gab Schwefelwasserstoff einen starken schwarzen in Salzsäure fast völlig klar wieder auflüslichen Niederschlag. Es waren indessen Spuren von Eisenjodid durch Kaliumeisencyanür, so wie auch durch Schwefelcyankalium auf Zusaiz einiger Tropfen. Salzsäure darin deutlich nachzuweisen.

Die Bildung von Eisenoxyd wird hier jedenfalls durch die reducirende Wirkung des Zuckers verhindert, indessen trïbt sich der mit Wasser stark verdünnte Syrup beim Stehen an der Luft im-Laufe einiger Tage, indem sich elwas Eisenoxyd daraus absclseidet. Da nun der Syrupus Ferri jodati lange Zeit der freien I.uft ausgesetzt, unverändert blcıbt: so dürfte, im Falle das Ferrum jodatum hä́ufiger in der fieceptur angewendet werden sollte, diese von Frederking empfohlene Methode, dasselbe als Medicament aufzubewahren und zu dispensiren, vielleicht Aufnahme finden.

Diese Miltheilurigen des Herrn $\mathrm{F}$ is c b e $\mathbf{r}$ bestätigen die Erfahrung des Herrn Frederking vollkommen und nicht leicht wird, wie es scheint, eine passlichere Arzneiform des Eisenjodürs, als cben dieser Syrup gefunden werden können. Mit Vergniigen entspreche ich daher der Aufforderung meines 
Marx: Ueber die Bildung des Gypses.

frühern Zuhörers und Freundes in Riga, seinen Vorschlag nach vorangegangener Prüfung zu veröffentlichen.

H. Wackenroder.

\author{
Zweite Abtheilung. \\ Naturgeschichte. \\ Ueber die Bildung des Gypses; \\ ron \\ C. Marx.
}

Die Frage nach der Entstelunng des Gypses ist eine der wichligsten in der Naturgeschichte der Erde. Es scheint jeizt beinahe ein Glanbensartikel der ineisten neueren Geognosten zu seyn, dass weitaus die bedeutendsten Gyps - Gebürge vulkanischen Ursprungs, dass sie Eindringlinge von unten herauf seyen, welche bei ibrem Emporsteigen alle Lagerungs - Verhällnisse in ihrer Umgebung verworfen und verändert hahen. Auch känn man in Wahrheit bei aufmerksamem und yergleichendem Ueberblick auf die äusseren und innern Beziehurgen dieser Formation kaum anders als eine gewaltsame Erzeugung derselben glauben. Es sind melır oder minder ausgedehnte, slockförmige Massen, von unerreichbarer Erstreckung in die Tiefe, meist eingekeilt zwischen andere fremdartige Bildungen, an deren Seiten oder Gipfel sie hervortreten, ohne erkennbare Ordnung und Schichtung, zerrissen und zerklüftet; oder sie erbeben sich ähnlich den Basalikuppen inselarlig aus den Niederungen, am Fusse der Gebirge. Die Schichten der sie begränzenden Gebirgsarten sind meistens aufgerichlet, verschoben, mit Höblungen und Schlotten durchzogen urid an den Berührungsstellen mannigfach umgewandelt. Auch finden sich in ihrer Näbe häufig noch die Zeugen fortdauernder unterirdischer Thätigkeiten, die Gasquellen, Thermen, Schwefelwässer und andere Mineralquellen.

So unzweifelhaft also die Entstehung der Gyps - Berge durch. plötzliche Nalurgewalten sich darstellt, so schwierig scheint die Erklärung davon zu seyn. Sie ist es jedorh 